\title{
HARE-Mediated Endocytosis of Hyaluronan and Heparin Is Targeted by Different Subsets of Three Endocytic Motifs
}

\author{
Madhu S. Pandey, ${ }^{1}$ Edward N. Harris, ${ }^{2}$ and Paul H. Weigel ${ }^{3}$ \\ ${ }^{1}$ Department of Biochemistry \& Molecular Biology, Penn State Hershey College of Medicine, Hershey, PA 17033, USA \\ ${ }^{2}$ Department of Biochemistry, University of Nebraska, Lincoln, NE 68588, USA \\ ${ }^{3}$ Department of Biochemistry \& Molecular Biology, Oklahoma Center for Medical Glycobiology and University of \\ Oklahoma Health Sciences Center, Oklahoma City, OK 73104, USA
}

Correspondence should be addressed to Paul H. Weigel; paul-weigel@ouhsc.edu

Received 22 October 2014; Accepted 21 December 2014

Academic Editor: H. Benjamin Peng

Copyright (C) 2015 Madhu S. Pandey et al. This is an open access article distributed under the Creative Commons Attribution License, which permits unrestricted use, distribution, and reproduction in any medium, provided the original work is properly cited.

\begin{abstract}
The hyaluronan (HA) receptor for endocytosis (HARE) is a multifunctional recycling clearance receptor for 14 different ligands, including HA and heparin (Hep), which bind to discrete nonoverlapping sites. Four different functional endocytic motifs ( $M$ ) in the cytoplasmic domain (CD) target coated pit mediated uptake: (YSYFRI ${ }^{2485}$ (M1), FQHF ${ }^{2495}$ (M2), NPLY ${ }^{2519}$ (M3), and DPF ${ }^{2534}$ (M4)). We previously found (Pandey et al. J. Biol. Chem. 283, 21453, 2008) that M1, M2, and M3 mediate endocytosis of HA. Here we assessed the ability of HARE variants with a single-motif deletion or containing only a single motif to endocytose HA or Hep. Single-motif deletion variants lacking $M 1, M 3$, or $M 4$ (a different subset than involved in HA uptake) showed decreased Hep endocytosis, although $M 3$ was the most active; the remaining redundant motifs did not compensate for loss of other motifs. Surprisingly, a HARE CD variant with only M3 internalized both HA and Hep, whereas variants with either M2 or M4 alone did not endocytose either ligand. Internalization of HA and Hep by HARE CD mutants was dynamin-dependent and was inhibited by hyperosmolarity, confirming clathrin-mediated endocytosis. The results indicate a complicated relationship among multiple CD motifs that target coated pit uptake and a more fundamental role for motif $M 3$.
\end{abstract}

\section{Introduction}

Stabilin-2 (Stab2) and HARE (half-length Stab2) function as primary scavenger receptors for the systemic clearance from lymph and blood of hyaluronan (HA) [1], heparin (Hep), and 12 other functionally and structurally distinct ligands [2-6]. HA turnover and catabolism by HARE have been studied extensively for decades $[1,7,8]$ and the responsible receptor was molecularly identified $>15$ years ago after it was purified and cloned $[5,6,9,10]$. HARE endocytosis of HA occurs over a broad range of sizes from $\sim 2.5 \mathrm{kDa}$ to $>\mathrm{MDa}$ [11]. Hep is cleared from the body by two different mechanisms: larger Hep is rapidly cleared from blood in a high-affinity saturable binding mechanism by HARE/Stab2 in liver sinusoidal endothelial cells $[12,13]$, whereas low mass Hep is primarily cleared by kidney [14] in a nonsaturable renal excretion mechanism [15].

HA and Hep have distinct binding sites within the HARE ectodomain and neither ligand competes for the binding and endocytosis of the other [2]. Several articles in this special issue summarize the many functions of HA. As with HA, the biological and clinical activities of Hep have been studied for decades, and Hep is the most highly prescribed drug in the USA (e.g., for preventing or treating thromboembolic diseases and postsurgery clotting) [16]. HA is synthesized by many cell types and is the longest (up to $5 \times 10^{4}$ sugars) and only unsulfated glycosaminoglycan. In contrast, Hep is synthesized by mast cells as a serglycin proteoglycan with much shorter polysaccharide chains, <50 sugars [17, 18]. Hep is the most anionic glycosaminoglycan, due to extensively sulfated disaccharide isomers and binds to many different matrix, soluble, and cell surface proteins, including growth factors [19]. Hep also functions as a coreceptor or anticoagulant agent [20,21].

Many receptors require bound ligand in order to interact with adapter proteins and then be targeted to coated pits [22]. In contrast, HARE and other constitutively recycling 
clearance receptors (e.g., asialoglycoprotein and LDL receptors) are continuously targeted to coated pits, internalized, and recycled back to the cell surface whether bound to ligand or not. Endocytic receptors often contain a tyrosine-based motif (e.g., YXX $\varphi$ or NPXY, where X is any amino acid and $\varphi$ is a hydrophobic residue) or a dileucine motif (D/EXXXLL/I) involved in clathrin-mediated endocytosis [23-26]. YXX $\varphi$ and dileucine motifs interact with AP-2 adaptor complexes, whereas NPXY motifs interact with AP-2 and other adaptor proteins such as Dab2 and ARH [25]. The adaptor protein GULP is required for Stab2-mediated phagocytosis of aged (apoptotic) red blood cells, by recognition of a phospho-Tyr in the HARE CD [27].

The 72-amino acid C-terminal tail of HARE $\left(\mathrm{Y}^{2480}-\mathrm{L}^{2551}\right.$ in full-length Stab2) contains at least four endocytic motifs, an unusually high number: YSYFRI ${ }^{2485}$ (M1), FQHF ${ }^{2495}$ (M2), NPLY ${ }^{2519}$ (M3), and DPF ${ }^{2534}$ (M4). Surprisingly, three of these four motifs (M1, M2, and M3) mediate endocytosis of HA, with $M 3$ being the most active motif [26]. All three motifs participate in total coated pit targeting of HARE-HA complexes, and no single motif is required for uptake if the other functional motifs are present. The HARE CD motif network responsible for targeting the receptor to coated pits reflect either a very high level of redundancy or the presence of multiple distinct endocytic and signaling pathways. Our objective here was to identify the endocytic motifs responsible for HARE-Hep endocytosis. The results indicate that M1, M3, and M4 are utilized for Hep endocytosis, which is a different subset of three motifs compared to that used for $\mathrm{HA}$, and that in the absence of other motifs, only $M 3$ is able to mediate the endocytosis of both HA and Hep; HARE containing $M 2$ or M4 alone did not mediate HA or Hep endocytosis.

\section{Methods}

2.1. Reagents, Buffers, Stable Cell Lines, and Normalization. Flp-In 293 cells, FBS, DMEM, hygromycin B, Zeocin, Lipofectamine 2000, glutamate, plasmid expression vectors, and super-competent TOP10 Escherichia coli were from InVitrogen (Carlsbad, CA). Stable cells expressing HARE and HARE-mutants were generated as described previously [26, 28]. Hep was from Celsus (Cincinnati, OH) or SigmaAldrich (St. Louis, MO). Low endotoxin HA, made by bacterial fermentation, was from Genzyme Corp. (Cambridge, MA). Dynasore was from Sigma-Aldrich. Sodium ${ }^{125} \mathrm{I}$-iodide $(100 \mathrm{mCi} / \mathrm{mL}$; specific activity of $>0.6 \mathrm{TBq} / \mathrm{mg})$ in $\mathrm{NaOH}$ and PD-10 columns were from GE/Amersham Biosciences (Piscataway, NJ). Streptavidin (SA) was from Pierce (Rockford, IL). Preparation and quantification of biotinylated and iodinated ligands and the compositions of other buffers were described previously $[13,29,30]$. Other materials, reagents, and kits were obtained as described [26] or were from Sigma-Aldrich. HARE cDNA constructs and vectors for creation of stably transfected Flp-In 293 cell lines expressing wildtype (WT) HARE or HARE mutants with single or multiple endocytic motif deletions or site-specific substitutions were described previously $[26,28]$. All recombinant HARE proteins contain C-terminal V5 and $\mathrm{His}_{6}$ epitope tags. Endocytosis Medium is DMEM with 0.05\% BSA. In all experiments, the results among different HARE-expressing cell lines were normalized for HARE expression based on Western blot quantification of equal lysate protein samples [26]. Binding or endocytosis result values are expressed as the mean $\pm \mathrm{SE} \mathrm{fmol} / 10^{6}$ cells/HARE.

2.2. ${ }^{125} I-S A \bullet b-H e p$ Binding and Endocytosis Assays. Cells expressing WT HARE, HARE-mutants, or EV were grown in DMEM with $8 \% \mathrm{FBS}$ and $100 \mu \mathrm{g} / \mathrm{mL}$ hygromycin B (complete medium) in 12-well tissue culture plates for at least 2 days prior to experiments. They were processed for binding or endocytosis assays at 90-95\% confluence. Radiolabeled ${ }^{125} \mathrm{I}$ SA $\bullet$ b-Hep or ${ }^{125} \mathrm{I}-\mathrm{SA} \bullet \mathrm{b}-\mathrm{HA}$ complexes were prepared [13] using a 2:1 molar ratio of b-GAG: ${ }^{125} \mathrm{I}-\mathrm{SA}$ and were incubated in $0.5 \mathrm{~mL}$ of Endocytosis Medium for $1 \mathrm{~h}$ on a rotary mixer at $22^{\circ} \mathrm{C}$ just prior to the experiment. For nonspecific binding controls, the same amounts of ${ }^{125} \mathrm{I}-\mathrm{SA}$ and free biotin were used. ${ }^{125}$ I-Complexes were diluted in Endocytosis Medium to the final concentrations indicated. Cells were washed with Hanks' balanced salts solution and incubated at $37^{\circ} \mathrm{C}$ for $1 \mathrm{~h}$ with Endocytosis Medium (no serum) to allow HARE-mediated internalization of any bound serum glycosaminoglycans. The medium was aspirated and replaced with Endocytosis Medium containing $50 \mathrm{nM}$ preformed complexes of ${ }^{125} \mathrm{I}$-SA with b-Hep or b-HA with or without a 50 -fold excess of unlabeled ligand as competitor. The cells were then incubated either at $37^{\circ} \mathrm{C}$ for 1,2 , or $4 \mathrm{~h}$ to assess the rate of endocytosis or at $4^{\circ} \mathrm{C}$ for $2 \mathrm{~h}$ with or without $0.055 \%$ digitonin to assess total cellular or surface binding, respectively [31].

Nonspecific binding of ${ }^{125} \mathrm{I}-\mathrm{SA}$ was also assessed in parallel samples by incubating cells with ${ }^{125} \mathrm{I}$-SA $\bullet$ biotin complexes. The medium was removed by aspiration, and cells were washed three times ( $2 \mathrm{~mL}$ each) with cold Hanks' balanced salts solution to remove unbound ligand and solubilized in $1 \mathrm{~mL} 0.3 \mathrm{~N} \mathrm{NaOH}$. Radioactivity was measured using a Packard Cobra II gamma counter and lysate protein content was determined by the method of Bradford [32] using bovine serum albumin as standard. For each cell line, including $\mathrm{EV}$, the binding of ${ }^{125} \mathrm{I}$-SA $\bullet$ biotin was subtracted from the binding of ${ }^{125} \mathrm{I}-\mathrm{SA} \bullet \mathrm{b}$-ligand to correct for nonspecific binding of SA.

\subsection{Treatment with Dynasore or Sucrose. WT, HARE} mutants, or EV cells were preincubated in Endocytosis Medium as noted above and then incubated at $37^{\circ} \mathrm{C}$ for 30 min with DMSO alone or $300 \mu \mathrm{M}$ dynasore, as indicated. ${ }^{125} \mathrm{I}$-Complexes in Endocytosis Medium were then added to a final concentration of $50 \mathrm{nM}$ and the cells were incubated at $37^{\circ} \mathrm{C}$ for $4 \mathrm{~h}$. For hyperosmolar treatment, preincubated cells were further incubated in Endocytosis Medium with or without $0.45 \mathrm{M}$ sucrose at $37^{\circ} \mathrm{C}$ for $30 \mathrm{~min}$. After $30 \mathrm{~min}$, medium was removed, and Endocytosis Medium with or without $0.45 \mathrm{M}$ sucrose containing $50 \mathrm{nM}{ }^{125} \mathrm{I}$-ligand was added and the cells were incubated at $37^{\circ} \mathrm{C}$ for $4 \mathrm{~h}$. The medium was aspirated and cells were washed three times 


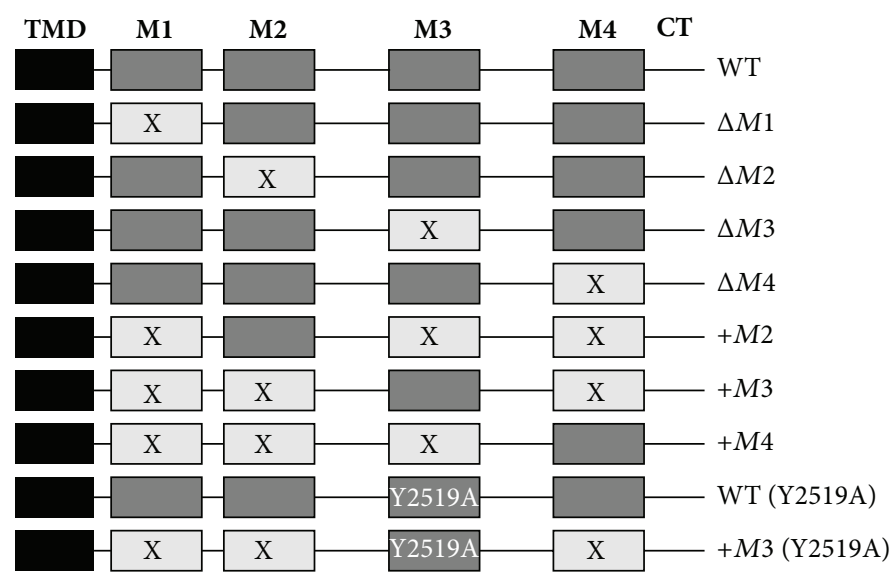

FIGURE 1: HARE CD mutants with different combinations of the four endocytic motifs. The diagram illustrates the various combinations of HARE CD motifs (M1, M2, M3, and M4) present (dark gray boxes) or deleted (light gray boxes with X) in the panel of stable HARE-CD variant cell lines used here. The single transmembrane domain (TMD, black box), C-terminal region (CT), and presence of the site-specific Y2519A mutation in M3 are indicated.

(2 mL each) with cold Hanks' balanced salts solution to remove unbound ${ }^{125}$ I-ligand and processed as noted above.

2.4. Statistical Analysis. At least 2-4 independent experiments were performed in triplicate $(n=6-12)$ and combined data are presented as the mean $\pm \mathrm{SE}$. All regression lines had correlation coefficients $\geq 0.97$ and experimental and control results were compared by unpaired Student's $t$-tests using SigmaPlot v10 (Systat Software, Inc., Point Richmond, CA). Values of $P<0.05$ were considered statistically significant.

\section{Results}

HARE and Stab2 are scavenger receptors that bind and clear 14 different ligands, including seven glycosaminoglycans, from lymph and blood. We designate the full-length $315 \mathrm{kDa}$ protein as Stab2 and HARE as the $190 \mathrm{kDa}$ isoform generated by an unknown proteolytic mechanism [33]. Both HARE/Stab2 are the main systemic clearance receptors for HA and presumably Hep, in all mammals studied [34-37]. HARE is the predominant Stab2-related protein expressed in sinusoidal endothelial cells of lymph node and liver, the main systemic clearance tissues [10,38]. Although both HA and Hep are anionic glycosaminoglycans, they bind to discrete and nonoverlapping sites in the HARE ectodomain [2]. HA binding requires the Link domain, which it likely binds to directly, whereas Hep binds to an uncharacterized site and binding is unaffected by deletion of the Link domain [2]. Since, HA and Hep bind to different sites, we wanted to determine if HARE utilizes the same subset of three redundantly functional endocytic motifs for Hep endocytosis as found previously for HA endocytosis [26]. Most of the CD mutants used here had been characterized previously for their HARE-mediated HA binding and uptake ability. Two additional single-motif containing CD mutants were created for the present study $(+M 2$ and $+M 4)$ to obtain a set of HARE $\mathrm{CD}$ variants expressing only one of the four motifs (e.g., $\Delta M 1 M 2 M 4=+M 3)$; the panel of CD mutants used is shown schematically in Figure 1. We were not successful in creating cell lines expressing only motif $M 1$.

3.1. Cell Surface and Total Hep Binding Are Similar among Multiple HARE CD Mutants. To understand further the importance of human HARE having the ability to internalize both HA and Hep, we wanted to determine which of the four CD endocytic motifs were functional for each ligand. We previously found that HARE expression levels, as well as HA binding to surface and intracellular HARE, were similar to WT in a panel of stable Flp-In 293 cell lines expressing various CD-mutants [26]. Here we used a set of variant cell lines, expressing HARE mutants that were either single-motif deletions or containing a single-motif (i.e., three motifs deleted). To determine whether the cellular HARE distribution of Hep binding was affected in any of the variants, we compared ${ }^{125} \mathrm{I}-\mathrm{SA} \bullet \mathrm{b}-\mathrm{Hep}$ binding at $4^{\circ} \mathrm{C}$ to cell surface or total cellular HARE (cell surface and intracellular receptors) in the various HARE CD-mutant cells. Total and surface binding were monitored in the presence or absence of digitonin, respectively, under conditions that selectively permeabilize endocytic, but not nuclear, mitochondrial or lysosomal compartments [31,39]. Since Hep nonspecifically binds to many cell surface and intracellular proteins, the binding of Hep by EV cells is higher relative to WT cells than the nonspecific binding of HA $[13,26]$. Only small amounts of ${ }^{125} \mathrm{I}$-SA $\bullet$ biotin (e.g., $<1 \%$ of ${ }^{125} \mathrm{I}-\mathrm{SA} \bullet \mathrm{b}-\mathrm{Hep}$ values) bound to cells and this did not increase with time [13]. In contrast, ${ }^{125} \mathrm{I}-$ SA $\bullet$ b-Hep uptake was time-dependent and linear over $4 \mathrm{~h}$, as in Figure 3.

Cell surface (Figures 2(a), 2(c), and 2(e)) and total (Figures 2(b), 2(d), and 2(f)) ${ }^{125} \mathrm{I}-\mathrm{SA} \bullet \mathrm{b}-\mathrm{Hep}$ binding to WT or HARE CD-mutant cells were 2-3 times greater than to EV cells.As expected, the distribution of ${ }^{125} \mathrm{I}-\mathrm{SA} \bullet \mathrm{b}-\mathrm{Hep}$ binding sites between surface and internal was similar to that for HA binding in WT and the HARE CD mutants [26]. HARE is a constitutively active receptor involved in continuous and repeated cycles of ligand internalization and the HARE 


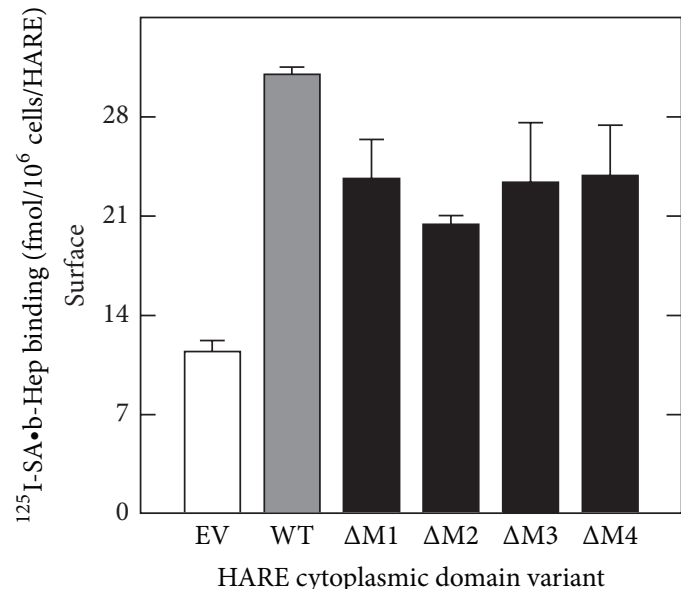

(a)

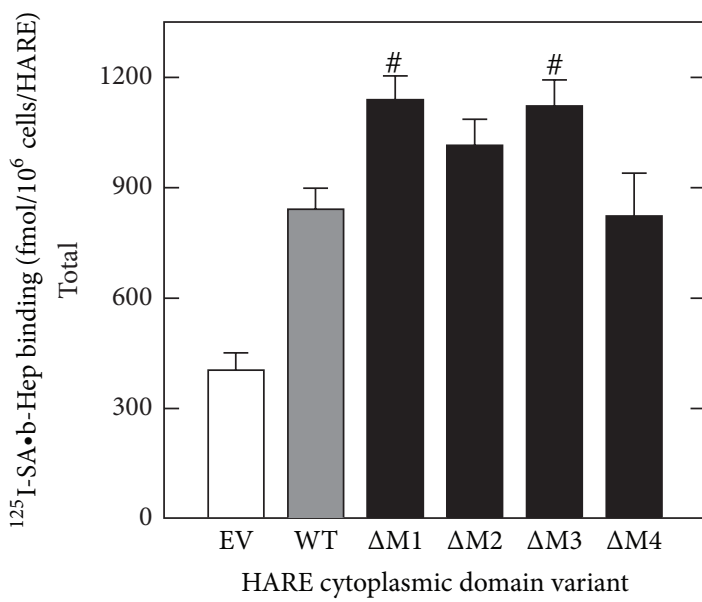

(b)

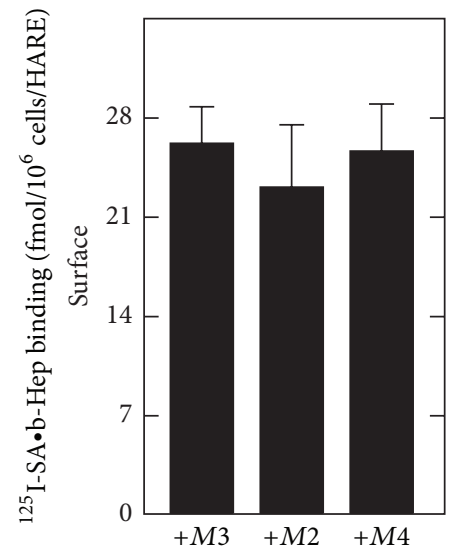

HARE cytoplasmic domain variant

(c)

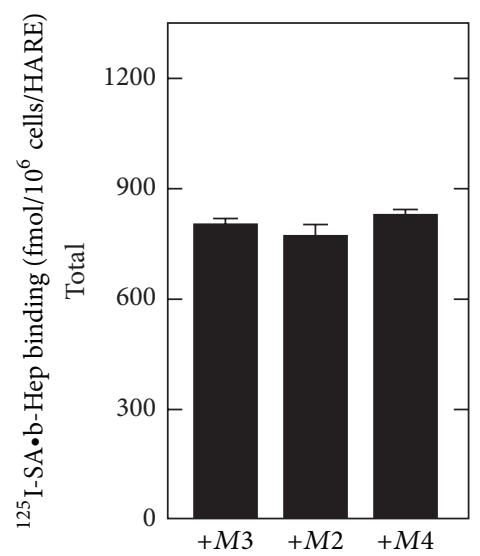

HARE cytoplasmic domain variant

(d)

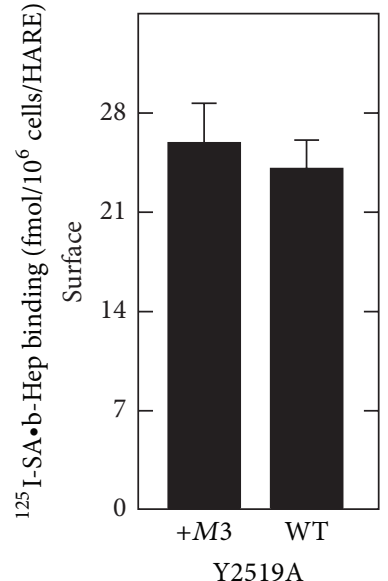

HARE cytoplasmic domain variant

(e)

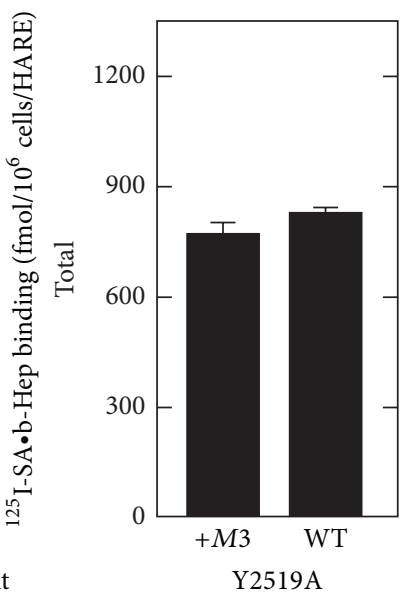

HARE cytoplasmic domain variant

(f)

FIGURE 2: Hep binding to cell surface and total HARE in CD variants. Cells expressing human HARE (WT), the indicated HARE CD mutants, or EV were grown, washed, and preincubated in Endocytosis Medium at $37^{\circ} \mathrm{C}$ for $1 \mathrm{~h}$ to allow clearance of serum-derived glycosaminoglycans bound to HARE. Cells were chilled to $4^{\circ} \mathrm{C}$, washed, and incubated with ${ }^{125} \mathrm{I}-\mathrm{SA} \bullet \mathrm{b}-\mathrm{Hep}$ complexes at $4^{\circ} \mathrm{C}$ and processed as described in Methods section to determine cell surface $(\mathrm{a}, \mathrm{c}, \mathrm{e})$ or total cellular $(\mathrm{b}, \mathrm{d}, \mathrm{f})$ specific ${ }^{125} \mathrm{I}-\mathrm{SA} \bullet \mathrm{b}-\mathrm{Hep}$ binding. Values are means \pm SE $(n=6-9)$ and significant differences (assessed by Student's $t$-test) between WT and a HARE CD variant are indicated: ${ }^{\#} P<0.05$.

recycling time of $7-9$ min $[28,40]$ is similar to that of other constitutively active recycling receptors $[13,41,42]$. The majority of recycling receptors, including HARE [28, 33], are localized in intracellular endocytic and recycling compartments. Thus, Hep total binding (surface and internal) by WT or CD-mutant cells was much greater than surface binding, as expected. Among the group of nine CD-mutants examined, there were no significant differences in Hep surface binding (Figure 2 top panels), confirming that deletion of one or more endocytic motifs did not alter the dynamic ongoing movement of HARE to and from the cell surface; the steadystate surface receptor pool was similar among a set of HARE variants. Total Hep binding was identical to WT among the set of nine HARE mutants except for $\Delta M 1$ and $\Delta M 3$ (Figure 2(b)), which were significantly higher $(P<0.05)$.
3.2. Internalization of ${ }^{125} I-S A \bullet b-H e p$ by HARE Single-Motif Deletion Mutants. To assess the contributions of the various endocytic motifs to the kinetics of Hep endocytosis, cells expressing WT, HARE-mutants, or EV were incubated at $37^{\circ} \mathrm{C}$ with ${ }^{125} \mathrm{I}$-SA $\bullet$ b-Hep for different times (Figure 3). Partial impairment of ${ }^{125} \mathrm{I}-\mathrm{SA} \bullet \mathrm{b}-\mathrm{Hep}$ endocytosis relative to $\mathrm{WT}$ cells occurred in $\Delta M 1$ or $\Delta M 4$ cells; HARE-specific uptake (WT uptake minus EV uptake) was $65 \%$ and $68 \%$ of WT rates, respectively, for $\Delta M 1$ or $\Delta M 4$ cells (Figure 3(a)). Cells expressing the $\Delta M 3$ mutant showed even greater impairment of HARE-specific Hep endocytosis (35\% of WT), indicating that $M 3$ is responsible for more targeting to coated pits than M1 or M4. Surprisingly, $\Delta M 2$ cells did not show a defect in HARE-specific Hep endocytosis, but rather a 35\% increase in HARE-specific uptake compared to WT as though M2 itself 


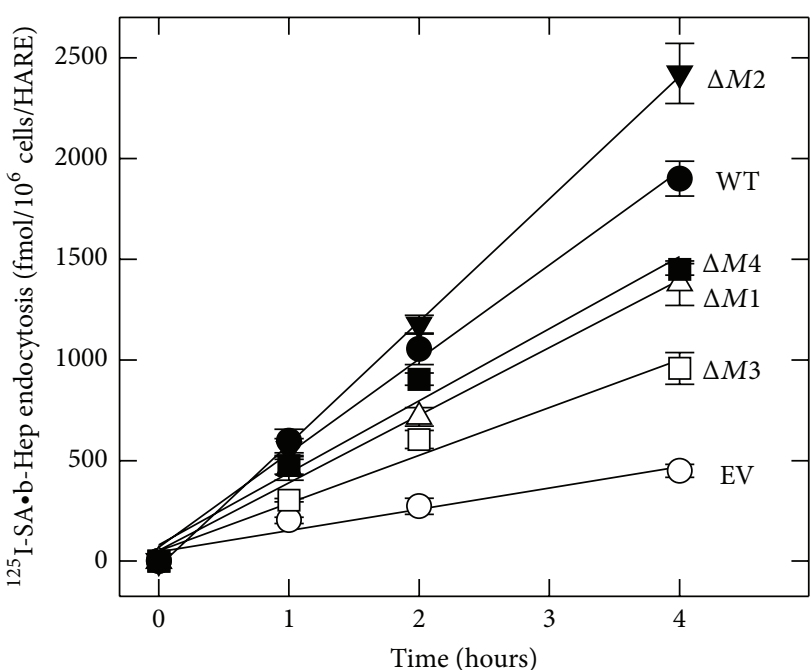

(a)

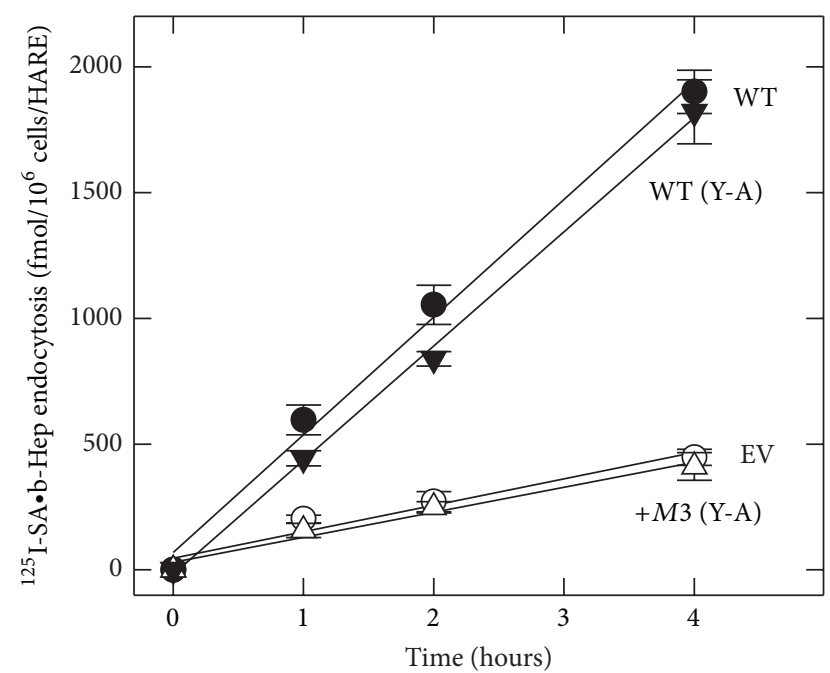

(b)

FIGURE 3: Hep endocytosis by cells expressing WT or HARE CD variants. Cells expressing WT (๑), EV (O), or HARE CD mutants ((a) $\triangle M 1$ $(\Delta), \Delta M 2(\boldsymbol{\nabla}), \Delta M 3(\square)$, and $\Delta M 4(\boldsymbol{\nabla})$ and $(\mathrm{b})+M 3(\mathrm{Y} 2519 \mathrm{~A})(\Delta)$, and WT $(\mathrm{Y} 2519 \mathrm{~A})(\boldsymbol{\nabla}))$ were pretreated and incubated with ${ }^{125} \mathrm{I}-\mathrm{SA} \bullet \mathrm{b}-\mathrm{Hep}$ complexes at $37^{\circ} \mathrm{C}$ as in Figure 2 for the indicated times to assess uptake rates as described in Methods section. Values are means $\pm \mathrm{SE}(n=9)$ and all linear regression lines had correlation coefficients $\geq 0.97$.

had an inhibitory effect on Hep uptake. Thus as found for HA endocytosis, three of the four motifs are involved in Hep uptake and no particular motif is absolutely required for Hep endocytosis, if the other three motifs are present. However, the subset of active motifs for Hep uptake (M1, M2, and M3) was not the same as that for HARE-HA complexes (M1, M3, and M4). Although M1 and M3 are used similarly for both HA uptake and Hep uptake, a different third motif is utilized by HARE for Hep (M4) versus HA (M2) endocytosis.

3.3. The Role of $Y^{2519}$ in HARE-Mediated Internalization of

${ }^{125} I-S A \bullet b$-Hep. Since it is well known that phosphorylated Tyr residues in NPXY motifs are important in signaling pathways $[43,44]$, we wanted to identify further the importance of $\mathrm{Y}^{2519}$ in NPLY ${ }^{2519}$ for targeting HARE-ligand complexes to coated pits. We used two CD-mutant HARE cell lines, one with only a Y-to-A substitution, WT (Y2519A), and the other with the same substitution in the $\triangle M 1 M 2 M 4$ background, + M3 (Y2519A). WT (Y2519A) cells showed no significant defect in ${ }^{125} \mathrm{I}$-SA $\bullet$ b-Hep endocytosis (95\% of specific WT uptake), whereas $+M 3$ (Y2519A) cells were identical to EV cells, showing complete impairment of Hep endocytosis (Figure 3(b)). The results show that Tyr in the HARE NPLY motif is critical for targeting to coated pits by $+M 3$ cells, but it is not required if HARE has functional M2 and M4 motifs; these motifs compensate for a potential defect in M3. The data are consistent with either the ability of NPLA ${ }^{2519}$ to retain targeting function in the presence of, but not the absence of, the two other Hep•HARE targeting motifs or the ability of M1 and M4 to compensate for NPLA ${ }^{2519}$ and perform the targeting function. taining Mutants. To address how multiple motifs function together to facilitate Hep endocytosis, we examined ${ }^{125} \mathrm{I}$ SA-ligand uptake in cells expressing different triple-motif deletions so that only single motifs remained (Figure 4). Interestingly, ${ }^{125} \mathrm{I}$-SA $\bullet$ b-Hep endocytosis by $+M 2$ or $+M 4$ cells was severely impaired by $\geq 95 \%$. In contrast $+M 3$ cells retained $65 \%$ of the HARE-specific endocytic capability of WT cells, an effect similar to the single-motif deletions $\Delta M 1$ or $\Delta M 4$. Based on studies with the single-motif deletion variants, especially $\Delta M 3$ cells, we expected that all three HARE CD variants containing only $M 2, M 3$, or $M 4$ would be able to target HARE-Hep complexes to coated pits and mediate effective uptake. Since $M 2$ does not participate in Hep uptake (Figure 3(a)), we expected $+M 2$ cells to be defective in Hep endocytosis. However, the inability of $+M 4$ cells to take up Hep was unexpected, since this motif is functional in WT cells. The unexpected functional differences among the single-motif containing HARE variants are not ligand specific, as the same pattern was observed when HA endocytosis was examined (Figure 4(b)). Again, $+M 2$ cells (expected to be active; Figure 4(a)) or $+M 4$ cells (expected to be inactive) were identical to EV cells; they were both unable to internalize HA, indicating the lack of coated pit targeting and uptake. In contrast $+M 3$ cells showed $\sim 60 \%$ of the endocytic capability of WT cells, a very similar result to that for Hep uptake (Figure 4(a)). Thus, although both HA (data not shown) and Hep (Figures 2(c) and 2(d)) bind equally well to HARE variants with only a single M2, M3 or M4 motif and these variants show similar surfaceinternal distributions (Figure 2), only $M 3$ by itself is able to target HARE-ligand complexes to coated pits and mediate efficient uptake. The quantitative and relative rates of ${ }^{125} \mathrm{I}$ $\mathrm{SA} \bullet \mathrm{b}-\mathrm{Hep}$ endocytosis of the various HARE CD mutants are summarized and compared to the values for HA uptake [26] in Table 1. 


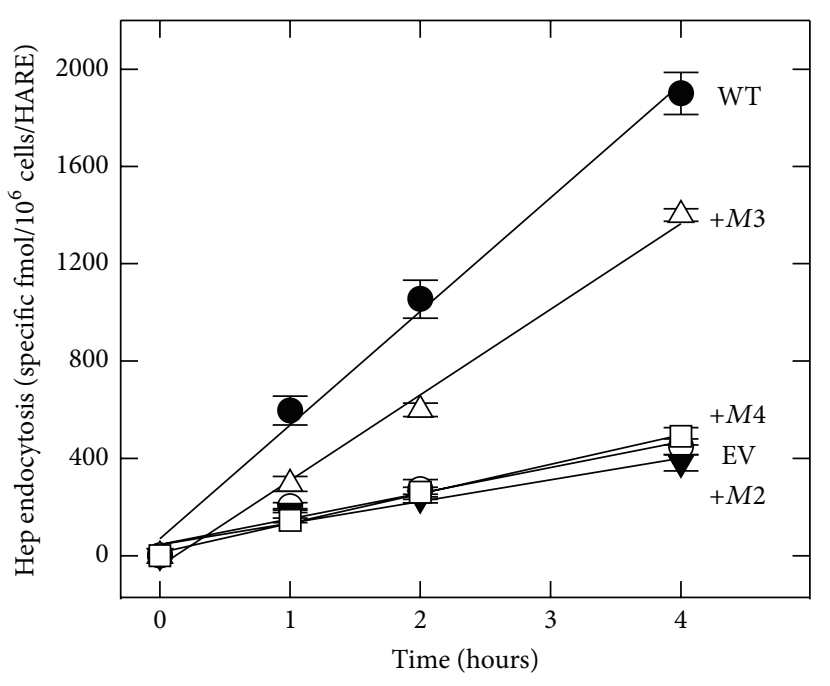

(a)

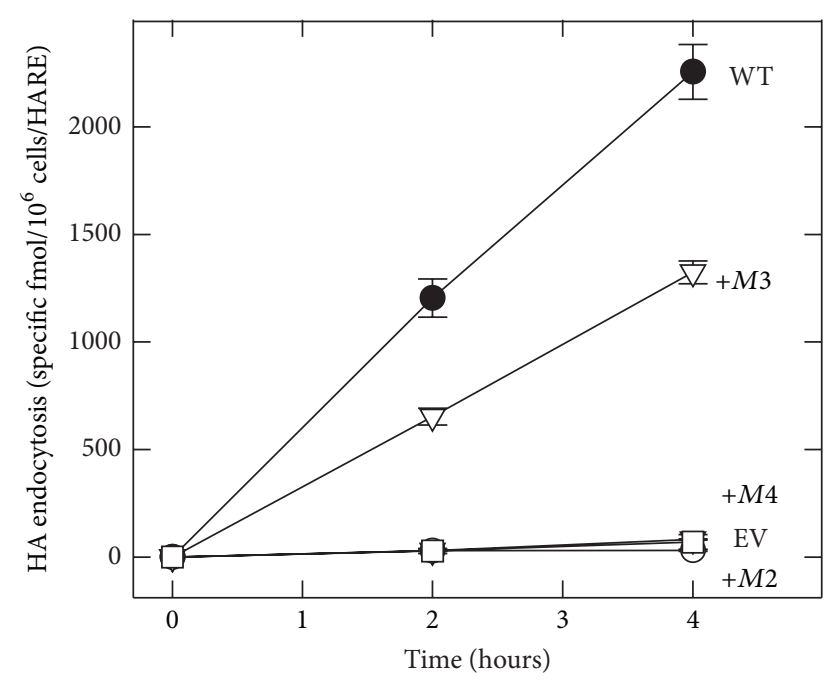

(b)

FIgURE 4: HARE mediates the endocytosis of HA or Hep in the presence of $M 3$ alone, but not in the presence of $M 2$ or $M 4$ alone. Cells expressing WT HARE $(\bullet)$, EV $(\bigcirc)$, or single-motif containing HARE CD variants $+M 2(\boldsymbol{\nabla}),+M 3(\Delta$ in $($ a); $\nabla$ in (b)), or $M 4$ ( $\square)$ were grown and treated as in Figure 2, incubated at $37^{\circ} \mathrm{C}$ for the indicated times with ${ }^{125} \mathrm{I}$-labeled Hep (a) or HA (b), and processed to quantify uptake as described in Methods section. Values are means \pm SE $(n=9)$ and all linear regression lines had correlation coefficients $\geq 0.97$. The three symbols for $\mathrm{EV},+M 2$, and $+M 4$ cells overlap at essentially identical positions in the bottom lines of each panel.

3.5. Internalization of Hep or HA by HARE CD Mutants Is Inhibited by Hyperosmolarity. The unexpected behavior of HARE single-motif containing variants prompted us to verify that the various HARE CD variants mediate endocytosis using a clathrin coated pit pathway, as shown previously for native and recombinant WT HARE [28, 40, 45]. Hyperosmolar conditions inhibit clathrin assembly into coated pits and, thus, clathrin-dependent internalization of many plasma membrane receptors [46-48]. To verify further that ligand uptake by the various HARE CD-mutant cells is clathrin-dependent, we assessed the effects of hyperosmolarity on endocytosis using medium containing $0.45 \mathrm{M}$ sucrose. Hyperosmolar sucrose treatment blocked internalization of HA by $\sim 77 \%$ in WT cells compared to control (untreated) cells and by $40-70 \%$ in the single-motif deletion HARE CD mutants (Figure 5(a)). Similar results were obtained for the effects of hyperosmolarity on Hep uptake (Figure 5(b)). Overall, the results confirm that Hep and HA internalization by the various HARE CD mutants occurs via clathrin-coated pit pathways.

3.6. Inhibition of Dynamin Activity Blocks HA or Hep Endocytosis by HARE. Many endocytic pathways in mammalian cells, including those involving clathrin-coated pits, phagocytosis, and caveolae, require the molecular motor protein dynamin for vesicle formation [49]. Dynasore is a small cell-permeable chemical that specifically inhibits the GTPase activity of dynamin and interferes with dynamin-dependent endocytic pathways [50]. Although not absolutely specific for clathrin-mediated uptake, dynasore should inhibit HAREmediated uptake that occurs via coated pits. Dynasore treatment significantly inhibited HA uptake by HARE CD variants with alterations in the motif subset involved in HA uptake, compared to DMSO-alone controls (Figure 6(a)).
Similarly, dynasore inhibited Hep endocytosis by $\sim 70-85 \%$ in several HARE CD mutants of the motif subset involved in Hep uptake (Figure 6(b)). As expected, the above dynasore and hyperosmolar sensitivity results indicate that the various HARE CD mutants mediate HARE-Hep and HAREHA endocytosis by dynamin-dependent clathrin-coated pit pathways.

\section{Discussion}

Full-length Stab2 and $190 \mathrm{kDa}$ HARE (the C-terminal half of Stab2) are the primary scavenger receptors for systemic clearance of multiple structurally distinct ligands (most of which are derived from tissue biomatrix degradation or cell debris) including $\mathrm{HA}, \mathrm{Hep}$, chondroitin sulfates (types A, C, D, and $\mathrm{E}$ ), dermatan sulfate, advanced glycation end products, acetylated or oxidized LDL, collagen $\mathrm{N}$-terminal propeptides, and $\alpha \mathrm{M} \beta 2$ and $\alpha 5 \beta 5$ integrins $[2,4,13,28,45,51-54]$. In addition, apoptotic cells and debris are rapidly cleared from blood and lymph by macrophages and sinusoidal endothelial cells via HARE-mediated binding to phosphatidylserine and then phagocytosis $[3,55]$. Both functional receptor isoforms are expressed in sinusoidal endothelial cells of liver, lymph node, spleen, and bone marrow with the $190 \mathrm{kDa}$ HARE being the predominant species [10]. Both are also expressed in some specialized tissues, such as corneal and lens epithelium, heart valve mesenchymal cells, epithelial cells in renal papillae, and oviduct [5]. HARE-mediated endocytosis of HA [56] or Hep [57] activates intracellular signaling leading to activation of ERK1/2 and NF- $\kappa$ B stimulation of gene expression. Uptake of the HARE ligands dermatan sulfate and acetylated LDL [57] and phosphatidylserine [55] also activated NF- $\kappa$ B mediated gene expression, whereas chondroitin sulfates types A, C, D, and $\mathrm{E}$ did not. Although all 9 of these ligands are effectively 
TABLE 1: Endocytosis of Hep or HA by WT or HARE CD mutants.

\begin{tabular}{lcccc}
\hline $\begin{array}{l}\text { HARE } \\
\text { variant }\end{array}$ & $\begin{array}{c}\text { Hep endocytosis } \\
\left(\mathrm{fmol} / 10^{6} \text { cells/HARE/h) }\right.\end{array}$ & $\begin{array}{c}\text { Specific Hep } \\
\text { endocytosis }(\%)\end{array}$ & $\begin{array}{c}\text { Specific HA } \\
\text { endocytosis }(\%)\end{array}$ & $\begin{array}{c}\text { HA endocytosis } \\
\left(\mathrm{fmol} / 10^{6} \text { cells/HARE/h) }\right.\end{array}$ \\
\hline EV & $110 \pm 10$ & 0 & 0 & $29.1 \pm 2.8$ \\
HARE (WT) & $480 \pm 20$ & 100 & 100 & $1204 \pm 89$ \\
$\Delta M 1$ & $350 \pm 30^{*}$ & 65 & 51 & - \\
$\Delta$ M2 & $\mathbf{6 1 0} \pm \mathbf{4 0 ^ { * }}$ & $\mathbf{1 3 5}$ & $\mathbf{6 1}$ & - \\
$\Delta M 3$ & $240 \pm 20^{* *}$ & 35 & 44 & - \\
$\Delta$ M4 & $\mathbf{3 6 0} \pm \mathbf{1 0 ^ { * }}$ & $\mathbf{6 8}$ & $\mathbf{1 1 9}$ & - \\
+ M2 & $111 \pm 30$ & 0 & 0 & - \\
+ M3 & $350 \pm 10^{*}$ & 65 & 58 & - \\
+ M4 & $129 \pm 10$ & 5 & 0 & - \\
+ M3 (Y2519A) & $100 \pm 10^{* *}$ & 0 & 5 & - \\
WT (Y2519A) & $460 \pm 30$ & 95 & 94 & - \\
\hline
\end{tabular}

EV, WT HARE, or the indicated HARE CD mutant cells were assessed for their ability to endocytose ${ }^{125}$ I-labeled Hep or HA specifically and results were normalized to total protein (cell number) and HARE expression level relative to WT as described in Methods section. Values are the mean \pm SE $(n=6-12)$ rate of endocytosis or the rate of specific endocytosis (uptake by WT cells minus uptake by EV cells) relative to WT as $100 \%$; significant differences compared to WT are indicated: ${ }^{*} P<0.005 ;{ }^{* *} P<0.0005$. The relative specific HA endocytosis values for the $\mathrm{CD}$ variants examined previously [26] are included (third column), along with the HA values for $+M 2$ and $+M 4$ cells determined here (far right column), for comparison to the Hep endocytosis values. The single-motif deletion mutant cells ( $\Delta M 2$ and $\Delta M 4$ ) that show differential involvement in HA versus Hep endocytosis are highlighted (boldface font).

endocytosed, ERK1/2 and NF- $\kappa \mathrm{B}$ signaling pathways are activated by only about half of them.

We proposed that Stab2 and HARE have two important physiological functions: (i) to clear and degrade multiple ligands reflecting the status of tissue biomatrices, as first reported for HA, and (ii) to serve as a Tissue Stress Sensor System [58] that responds to the amounts and ratios of multiple biomatrix ligands via a signal transduction network that leads to the secretion of TGF- $\beta$ [59] and other, yet to be identified, factors such as pro- or anti-inflammatory cytokines. The physiological importance of HARE/Stab2 for HA homeostasis was verified in Stab2 knockout mice, which have impaired systemic clearance of HA resulting in abnormally high circulating HA levels [60]. Cytokine profiles have not yet been determined in these animals. HARE may also act as a homing receptor for human prostate tumor cells, allowing metastasis to lymph nodes [61] and likely other HARE-expressing tissues, such as liver and bone marrow. Metastasis was $>95 \%$ blocked by treating mice with a specific anti-HARE HA-blocking antibody.

It is well established that HARE-HA uptake is clathrin coated pit-mediated $[40,45]$, and this was confirmed for Hep uptake in various HARE CD mutants based on the inhibition of ligand uptake in cells treated with either the dynamin inhibitor dynasore or sucrose, under hyperosmolar conditions (Figures 5 and 6). Many endocytic receptors utilize a single CD motif for endocytosis, such as $\operatorname{YXX} \varphi$ (e.g., transferrin and asialoglycoprotein receptors $[62,63]$ ) or NPXY (e.g., LDL, insulin, and EGF receptors [64, 65]). To our knowledge few other, if any, receptors contain multiple different endocytic motifs that are cooperatively utilized for endocytosis. For example, LDL receptor-related protein contains five possible endocytic motifs $(1, \mathrm{YXX} \varphi ; 2$, NPXY; and 2, LL), but only $\operatorname{YXX} \varphi$ is utilized as the dominant endocytic signal [66]. HARE is unusual and possibly unique in having four different functional endocytic motifs and in utilizing subsets of three motifs for the uptake of HA and Hep.

An unexpected finding in this study was that HARE utilizes a different subset of three motifs for the endocytosis of Hep compared to HA (Figure 7). Three of the four endocytic motifs in the HARE CD (M1 (YSYFRI $^{2485}$ ), M3 (NPLY $\left.{ }^{2519}\right)$, and $M 4\left(\mathrm{DPF}^{2534}\right)$ ) are utilized for Hep internalization. In contrast, a different subset of three motifs $\left(M 1, M 2\left(\mathrm{FQHF}^{2595}\right)\right.$, and $\left.\mathrm{M} 3\right)$ is utilized for HA endocytosis [26]. This result and the previous finding that Hep and HA bind to independent nonoverlapping sites in the HARE ectodomain [2] indicate that the binding of HA or Hep may create distinct conformational states within the intracellular $\mathrm{CD}$ that promoted differential recognition of endocytic motifs $M 2$ and M4 by the relevant adaptor proteins. Different conformational or multimeric states of the intracellular CD could favor efficient binding of particular adaptor proteins to specific motifs. The CD conformation of HARE-HA complexes may allow $M 2$ recognition by an appropriate adaptor protein, but not $M 4$ recognition, whereas the CD conformation of HARE-Hep complexes may allow M4 recognition by an appropriate adaptor protein, but not M2 recognition. Consistent with the idea that binding in the ectodomain may influence intracellular signaling, Hep does not bind within the HA-binding HARE Link domain, whereas both HA and Hep bind to the Link domain of TSG6 [67].

The consequences of this differential mechanism of Hep versus HA endocytosis are unknown but might include different downstream signaling events or trafficking outcomes for a portion of the internalized pool of Hep or HA. The impairment of HA or Hep endocytosis due to a single-motif deletion was not compensated by the other two functional motifs, indicating that each motif mediates targeting and endocytosis by a distinct independent and saturable pathway, 


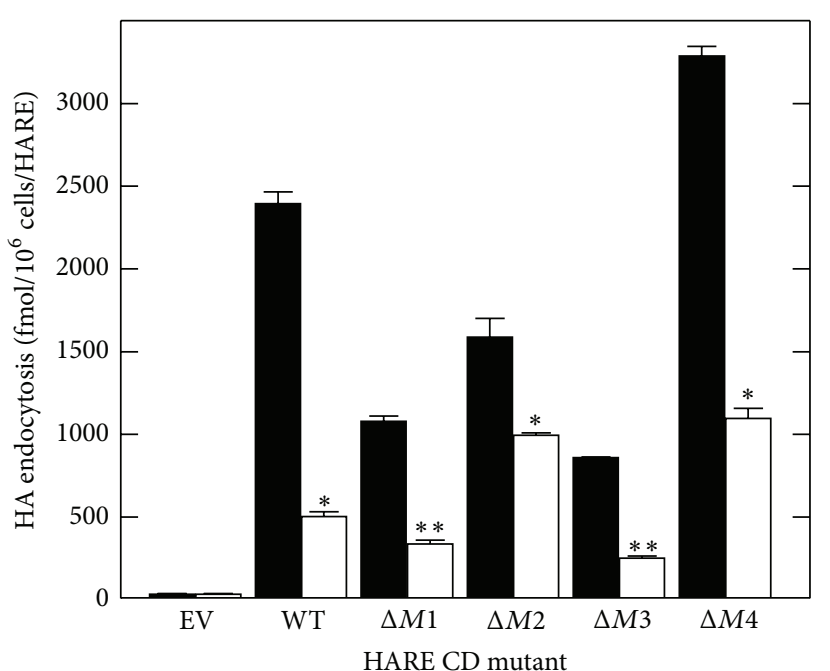

No sucrose Sucrose

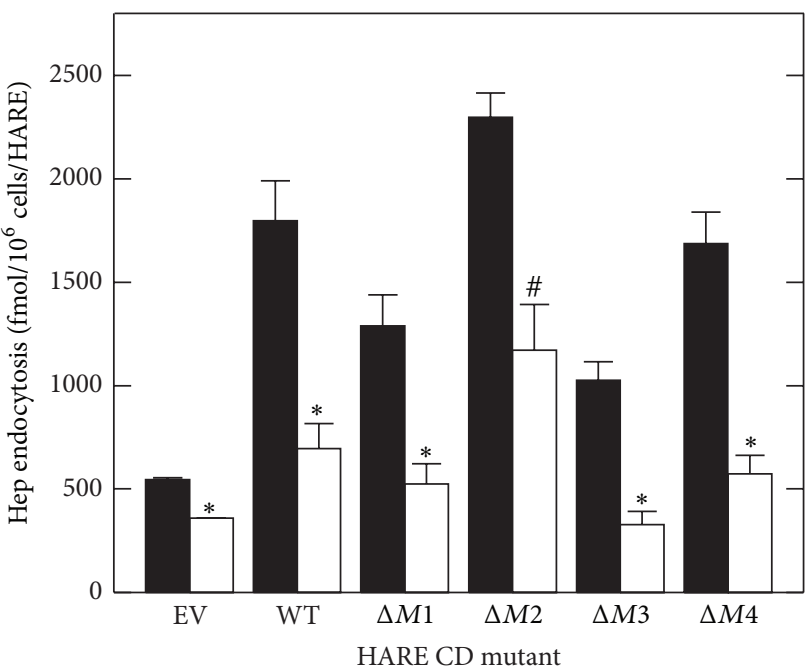

No sucrose Sucrose

(a)

(b)

FIGURE 5: Endocytosis of HA and Hep by HARE CD variants is blocked by hyperosmolar conditions. Cells expressing EV, WT, or the indicated single-motif deletion HARE CD mutants were grown and pretreated as in Figure 2 and then preincubated at $37^{\circ} \mathrm{C}$ for 30 min with Endocytosis Medium with (white) or without (black) $0.45 \mathrm{M}$ sucrose. The cells were then incubated with ${ }^{125}$ I-labelled HA (a) or Hep (b) at $37^{\circ} \mathrm{C} \mathrm{for} 4 \mathrm{~h}$ and processed as described in Methods section. Values are means \pm SE $(n=6)$ and significant differences (assessed by Student's $t$-test) between control and sucrose-treated samples are indicated: ${ }^{\#} P<0.05 ;{ }^{*} P<0.005 ;{ }^{* *} P<0.0005$.

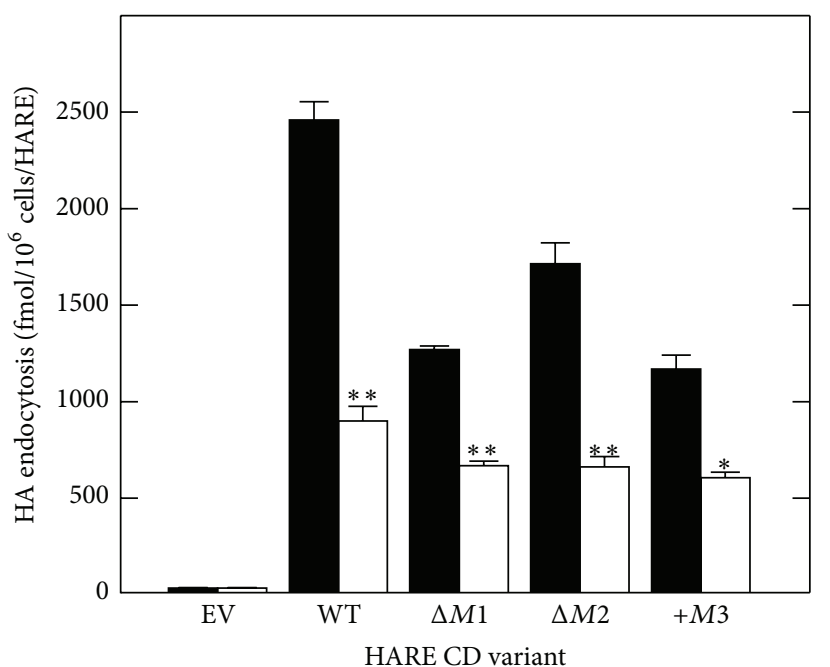

DMSO

Dynasore

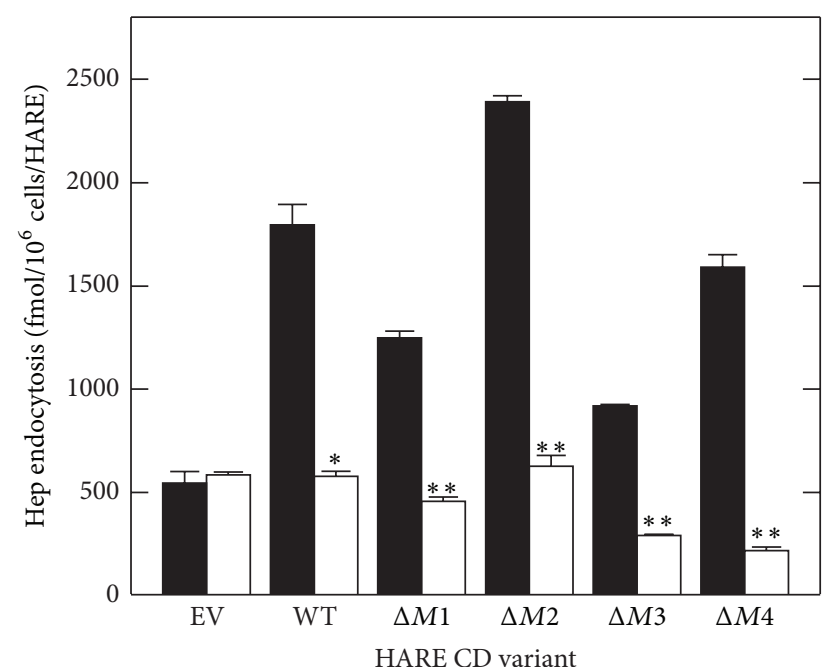

DMSO

Dynasore

(a)

(b)

FIGURE 6: Endocytosis of HA and Hep by HARE CD variants is blocked by a dynamin inhibitor. WT cells were washed and preincubated in Endocytosis Medium as in Figure 2 and pretreated in medium with DMSO alone (black) or with $300 \mu \mathrm{M}$ dynasore (white) at $37^{\circ} \mathrm{C}$ for 30 min. The medium was then replaced with fresh media containing DMSO alone or dynasore and ${ }^{125}$ I-labelled HA (a) or Hep (b). The cells were incubated at $37^{\circ} \mathrm{C}$ for $4 \mathrm{~h}$ and specific cell-associated ligand was determined as noted in Methods section. Values are the means $\pm \mathrm{SE}(n=3)$ and significant differences (Student's $t$-test) between treated and control samples are indicated: ${ }^{*} P<0.005 ;{ }^{* *} P<0.0005$. 


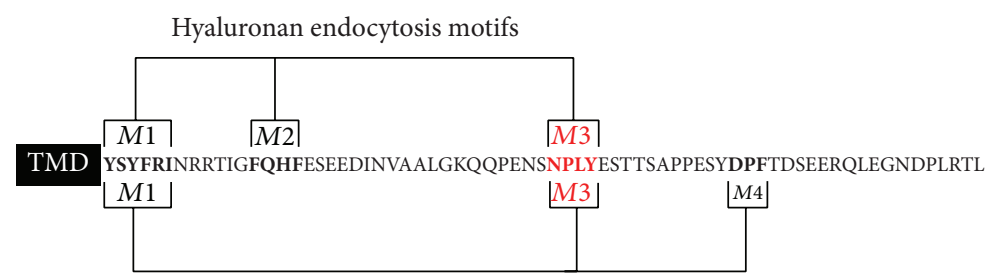

Heparin endocytosis motifs

FIGURE 7: Different sets of HARE CD endocytic motifs are functional during HA versus Hep endocytosis. The four HARE endocytic motifs (boldface) examined are denoted by $M 1\left(\mathrm{YSYFRI}^{2485}\right), M 2\left(\mathrm{FQHF}^{2495}\right), M 3\left(\mathrm{NPLY}^{2519}\right)$, and $M 4\left(\mathrm{DPF}^{2534}\right)$. The two different subsets of three of these motifs active in the coated pit mediated endocytosis of HA (M1, M2, and M3) or Hep (M1, M3, and M4) are highlighted by brackets. $M 3$ is highlighted in red to indicate its special significance as the only motif of the three we were able to test $(M 2, M 3$, and $M 4)$ that enabled HARE to target coated pit mediated endocytosis of both HA and Hep.

perhaps through a subset of coated pits. If true, this has significant implications for possible independent concurrent signaling pathways mediated by different HARE-ligand complexes. One difference between the signaling stimulated by HA uptake and the signaling stimulated by Hep uptake is that HA signaling is very size-dependent. Only HA sizes between $40 \mathrm{kDa}$ and $400 \mathrm{kDa}$ are able to activate HARE-mediated ERK1/2 and NF- $\kappa$ B signaling pathways; smaller or larger HA is endocytosed but does not activate signaling [11]. HAREHep activation of both signaling pathways is independent of Hep size [57]. Perhaps the use of different motif subsets for HA and Hep uptake is related to the mechanism by which HA size dependence is achieved during internalization of HAREHA complexes.

The results indicate that each subset of three motifs participates in the total uptake of HA or Hep, but that the nature of their cooperation is unequal and complicated. Although the loss of only $M 3$ (in $\Delta M 3$ cells) impaired Hep or HA endocytosis by $\sim 40 \%$, indicating that $M 3$ shares onethird of the Hep uptake burden, the loss of the other two Hep uptake motifs $M 1$ and $M 4$ (in $+M 3$ cells) only decreased endocytosis by the same amount, $35 \%$. This was a surprising functional difference among the three motifs, since they appear to function together when all are present, but only one can function if alone. Hep and HA endocytosis were completely eliminated in $+M 3$ (Y2519A) cells, showing that $\mathrm{Tyr}^{2519}$ is important for the endocytic process mediated by M3 alone. In WT (Y2519A) cells there was essentially no effect on uptake of either ligand. However, ongoing studies show that WT (Y2519A) cells are completely unable to activate NF$\kappa \mathrm{B}$ during uptake of HA, Hep, dermatan sulfate, or acetylated LDL [57]. Thus, Tyr $^{2519}$ is critical for signaling to downstream effectors, when the receptor is endocytosing loaded cargo, but it is not needed for just cargo endocytosis alone.

Further studies are required to define the adaptor proteins (e.g., Gulp or AP-2) that interact with the four endocytic motifs in the HARE CD and to understand the biological relevance of the complex coated pit targeting network and how it is coupled to signal transduction for a subset of internalized ligands.

\section{Abbreviations}

b-: A biotinyl group

CD: Cytoplasmic domain
EV: Empty vector

HA: Hyaluronic acid, hyaluronate, and hyaluronan

HARE: $190 \mathrm{kDa}$ human hyaluronic acid receptor for endocytosis

Hep: Heparin

M1: $\quad$ HARE CD motif 1 (YSYFRI)

M2: HARE CD motif 2 (FQHF)

M3: HARE CD motif 3 (NPLY)

M4: HARE CD motif 4 (DPF)

SA: Streptavidin

Stab2: Stabilin-2.

\section{Conflict of Interests}

The authors declare that there is no conflict of interests regarding the publication of this paper.

\section{Acknowledgments}

The authors thank Jennifer Washburn for excellent technical assistance. This research was supported by the National Institute of General Medical Sciences Grant GM69961 from the National Institutes of Health and by OCAST Grant HR10074 .

\section{References}

[1] J. R. E. Fraser, L. E. Appelgren, and T. C. Laurent, “Tissue uptake of circulating hyaluronic acid. A whole body autoradiographic study," Cell and Tissue Research, vol. 233, no. 2, pp. 285-293, 1983.

[2] E. N. Harris and P. H. Weigel, "The ligand-binding profile of HARE: hyaluronan and chondroitin sulfates A, C, and D bind to overlapping sites distinct from the sites for heparin, acetylated low-density lipoprotein, dermatan sulfate, and CSE," Glycobiology, vol. 18, no. 8, pp. 638-648, 2008.

[3] S.-Y. Park, M.-Y. Jung, H.-J. Kim et al., "Rapid cell corpse clearance by stabilin-2, a membrane phosphatidylserine receptor," Cell Death and Differentiation, vol. 15, no. 1, pp. 192-201, 2008.

[4] M. Y. Jung, S. Y. Park, and I. S. Kim, "Stabilin-2 is involved in lymphocyte adhesion to the hepatic sinusoidal endothelium via the interaction with alphaMbeta 2 integrin," Journal of Leukocyte Biology, vol. 82, no. 5, pp. 1156-1165, 2007. 
[5] M. Falkowski, K. Schledzewski, B. Hansen, and S. Goerdt, "Expression of stabilin-2, a novel fasciclin-like hyaluronan receptor protein, in murine sinusoidal endothelia, avascular tissues, and at solid/liquid interfaces," Histochemistry and Cell Biology, vol. 120, no. 5, pp. 361-369, 2003.

[6] O. Politz, A. Gratchev, P. A. G. McCourt et al., "Stabilin-1 and 2 constitute a novel family of fasciclin-like hyaluronan receptor homologues," Biochemical Journal, vol. 362, no. 1, pp. 155-164, 2002.

[7] T. C. Laurent and J. R. E. Fraser, "Catabolism of hyaluronan," in Degradation of Bioactive Substances: Physiology and Pathophysiology, J. H. Henriksen, Ed., pp. 249-264, CRC Press, Boca Raton, Fla, USA, 1991

[8] T. C. Laurent, I. M. S. Dahl, L. B. Dahl et al., "The catabolic fate of hyaluronic acid," Connective Tissue Research, vol. 15, no. 1-2, pp. 33-41, 1986.

[9] B. Zhou, J. A. Weigel, L. A. Fauss, and P. H. Weigel, "Identification of the hyaluronan receptor for endocytosis (HARE)," The Journal of Biological Chemistry, vol. 275, no. 48, pp. 37733-37741, 2000.

[10] B. Zhou, J. A. Oka, A. Singh, and P. H. Weigel, "Purification and subunit characterization of the rat liver endocytic hyaluronan receptor," Journal of Biological Chemistry, vol. 274, no. 48, pp. 33831-33834, 1999.

[11] M. S. Pandey, B. A. Baggenstoss, J. Washburn, E. N. Harris, and P. H. Weigel, "The hyaluronan receptor for endocytosis (HARE) activates NF- $\kappa \mathrm{B}$-mediated gene expression in response to $40-$ 400-kDa, but not smaller or larger, hyaluronans," Journal of Biological Chemistry, vol. 288, no. 20, pp. 14068-14079, 2013.

[12] E. N. Harris, B. A. Baggenstoss, and P. H. Weigel, "Rat and human HARE/stabilin-2 are clearance receptors for highand low-molecular-weight heparins," The American Journal of Physiology-Gastrointestinal and Liver Physiology, vol. 296, no. 6, pp. G1191-G1199, 2009.

[13] E. N. Harris, J. A. Weigel, and P. H. Weigel, "The human hyaluronan receptor for endocytosis (HARE/stabilin-2) is a systemic clearance receptor for heparin," Journal of Biological Chemistry, vol. 283, no. 25, pp. 17341-17350, 2008.

[14] D. L. Dinwoodey and J. E. Ansell, "Heparins, low-molecularweight heparins, and pentasaccharides," Clinics in Geriatric Medicine, vol. 22, no. 1, pp. 1-15, 2006.

[15] B. Boneu, C. Caranobe, and P. Sie, "Pharmacokinetics of heparin and low molecular weight heparin," Bailliere's Clinical Haematology, vol. 3, no. 3, pp. 531-544, 1990.

[16] R. Castelli, F. Porro, and P. Tarsia, "The heparins and cancer: review of clinical trials and biological properties," Vascular Medicine, vol. 9, no. 3, pp. 205-213, 2004.

[17] I. Pettersson, M. Kusche, E. Unger et al., "Biosynthesis of heparin. Purification of a $110-\mathrm{kDa}$ mouse mastocytoma protein required for both glucosaminyl $\mathrm{N}$-deacetylation and $\mathrm{N}$ sulfation," The Journal of Biological Chemistry, vol. 266, no. 13, pp. 8044-8049, 1991.

[18] D. Xu and J. D. Esko, "Demystifying heparan sulfate-protein interactions," Annual Review of Biochemistry, vol. 83, no. 1, pp. 129-157, 2014.

[19] J. Shute, "Glycosaminoglycan and chemokine/growth factor interactions," Handbook of Experimental Pharmacology, vol. 207, pp. 307-324, 2012.

[20] K. Norrby, "Low-molecular-weight heparins and angiogenesis," APMIS, vol. 114, no. 2, pp. 79-102, 2006.
[21] K. Mahtouk, D. Hose, T. Rème et al., "Expression of EGF-family receptors and amphiregulin in multiple myeloma. Amphiregulin is a growth factor for myeloma cells," Oncogene, vol. 24, no. 21, pp. 3512-3524, 2005.

[22] G. J. Doherty and H. T. McMahon, "Mechanisms of endocytosis," Annual Review of Biochemistry, vol. 78, pp. 857-902, 2009.

[23] I. Mellman, "Membranes and sorting," Current Opinion in Cell Biology, vol. 8, no. 4, pp. 497-498, 1996.

[24] A. Sorkin, "Cargo recognition during clathrin-mediated endocytosis: a team effort," Current Opinion in Cell Biology, vol. 16, no. 4, pp. 392-399, 2004.

[25] J. S. Bonifacino and L. M. Traub, "Signals for sorting of transmembrane proteins to endosomes and lysosomes," Annual Review of Biochemistry, vol. 72, pp. 395-447, 2003.

[26] M. S. Pandey, E. N. Harris, J. A. Weigel, and P. H. Weigel, “The cytoplasmic domain of the hyaluronan receptor for endocytosis (HARE) contains multiple endocytic motifs targeting coated pit-mediated internalization," Journal of Biological Chemistry, vol. 283, no. 31, pp. 21453-21461, 2008.

[27] S.-Y. Park, K.-B. Kang, N. Thapa, S.-Y. Kim, S.-J. Lee, and I.-S. Kim, "Requirement of adaptor protein GULP during stabilin2-mediated cell corpse engulfment," The Journal of Biological Chemistry, vol. 283, no. 16, pp. 10593-10600, 2008.

[28] E. N. Harris, J. A. Weigel, and P. H. Weigel, "Endocytic function, glycosaminoglycan specificity, and antibody sensitivity of the recombinant human $190-\mathrm{kDa}$ hyaluronan receptor for endocytosis (HARE)," The Journal of Biological Chemistry, vol. 279, no. 35, pp. 36201-36209, 2004.

[29] C. T. McGary, J. A. Weigel, and P. H. Weigel, "Study of hyaluronan-binding proteins and receptors using iodinated hyaluronan derivatives," Methods in Enzymology, vol. 363, pp. 354-365, 2003.

[30] Q. Yu and B. P. Toole, "Biotinylated hyaluronan as a probe for detection of binding proteins in cells and tissues," BioTechniques, vol. 19, no. 1, pp. 122-129, 1995.

[31] P. H. Weigel, D. A. Ray, and J. A. Oka, "Quantitation of intracellular membrane-bound enzymes and receptors in digitoninpermeabilized cells," Analytical Biochemistry, vol. 133, no. 2, pp. 437-449, 1983.

[32] M. M. Bradford, "A rapid and sensitive method for the quantitation of microgram quantities of protein utilizing the principle of protein dye binding," Analytical Biochemistry, vol. 72, no. 1-2, pp. 248-254, 1976.

[33] E. N. Harris, S. V. Kyosseva, J. A. Weigel, and P. H. Weigel, "Expression, processing, and glycosaminoglycan binding activity of the recombinant human $315-\mathrm{kDa}$ Hyaluronic Acid Receptor for Endocytosis (HARE)," The Journal of Biological Chemistry, vol. 282, no. 5, pp. 2785-2797, 2007.

[34] T. C. Laurent and J. R. E. Fraser, "Hyaluronan," The FASEB Journal, vol. 6, no. 7, pp. 2397-2404, 1992.

[35] J. R. E. Fraser, T. C. Laurent, A. Engstrom-Laurent, and U. G. B. Laurent, "Elimination of hyaluronic acid from the blood stream in the human," Clinical and Experimental Pharmacology and Physiology, vol. 11, no. 1, pp. 17-25, 1984.

[36] S. Eriksson, J. R. E. Fraser, T. C. Laurent, H. Pertoft, and B. Smedsrød, "Endothelial cells are a site of uptake and degradation of hyaluronic acid in the liver," Experimental Cell Research, vol. 144, no. 1, pp. 223-228, 1983.

[37] J. R. E. Fraser, T. C. Laurent, H. Pertoft, and E. Baxter, "Plasma clearance, tissue distribution and metabolism of hyaluronic acid injected intravenously in the rabbit," Biochemical Journal, vol. 200, no. 2, pp. 415-424, 1981. 
[38] B. Zhou, C. T. McGary, J. Weigel A., A. Saxena, and P. H. Weigel, "Purification and molecular identification of the human hyaluronan receptor for endocytosis," Glycobiology, vol. 13, no. 5, pp. 339-349, 2003.

[39] P. H. Weigel and J. A. Oka, "The large intracellular pool of asialoglycoprotein receptors functions during the endocytosis of asialoglycoproteins by isolated rat hepatocytes," The Journal of Biological Chemistry, vol. 258, no. 8, pp. 5095-5102, 1983.

[40] C. T. McGary, R. H. Raja, and P. H. Weigel, "Endocytosis of hyaluronic acid by rat liver endothelial cells: evidence for receptor recycling," Biochemical Journal, vol. 257, no. 3, pp. 875$884,1989$.

[41] S. K. Basu, J. L. Goldstein, R. G. W. Anderson, and M. S. Brown, "Monensin interrupts the recycling of low density lipoprotein receptors in human fibroblasts," Cell, vol. 24, no. 2, pp. 493-502, 1981.

[42] A. Ciechanover, A. L. Schwartz, A. Dautry Varsat, and H. F. Lodish, "Kinetics of internalization and recycling of transferrin and the transferrin receptor in a human hepatoma cell line. Effect of lysosomotropic agents," Journal of Biological Chemistry, vol. 258, no. 16, pp. 9681-9689, 1983.

[43] M. T. Uhlik, B. Temple, S. Bencharit, A. J. Kimple, D. P. Siderovski, and G. L. Johnson, "Structural and evolutionary division of phosphotyrosine binding (PTB) domains," Journal of Molecular Biology, vol. 345, no. 1, pp. 1-20, 2005.

[44] P. C. Stolt and H. H. Bock, "Modulation of lipoprotein receptor functions by intracellular adaptor proteins," Cellular Signalling, vol. 18, no. 10, pp. 1560-1571, 2006.

[45] B. Smedsrod, M. Malmgren, J. Ericsson, and T. C. Laurent, "Morphological studies on endocytosis of chondroitin sulphate proteoglycan by rat liver endothelial cells," Cell and Tissue Research, vol. 253, no. 1, pp. 39-45, 1988.

[46] J. A. Oka and P. H. Weigel, "Effects of hyperosmolarity on ligand processing and receptor recycling in the hepatic galactosyl receptor system," Journal of Cellular Biochemistry, vol. 36, no. 2, pp. 169-183, 1988.

[47] S. J. Zhu, L. I. Hatcher, J. C. Brown III, S. M. Whittle, and M. L. Toews, "Effects of hypertonic sucrose and potassium depletion on the binding properties of beta and alpha 1 adrenergic receptors measured on intact cells," Receptors \& Signal Transduction, vol. 6, no. 3-4, pp. 131-140, 1996.

[48] J. E. Heuser and R. G. W. Anderson, "Hypertonic media inhibit receptor-mediated endocytosis by blocking clathrin-coated pit formation," Journal of Cell Biology, vol. 108, no. 2, pp. 389-400, 1989.

[49] S. D. Conner and S. L. Schmid, "Regulated portals of entry into the cell," Nature, vol. 422, no. 6927, pp. 37-44, 2003.

[50] E. Macia, M. Ehrlich, R. Massol, E. Boucrot, C. Brunner, and T. Kirchhausen, "Dynasore, a cell-permeable inhibitor of dynamin," Developmental Cell, vol. 10, no. 6, pp. 839-850, 2006.

[51] B. Hansen, P. Longati, K. Elvevold et al., "Stabilin-1 and stabilin2 are both directed into the early endocytic pathway in hepatic sinusoidal endothelium via interactions with clathrin/AP-2, independent of ligand binding," Experimental Cell Research, vol. 303, no. 1, pp. 160-173, 2005.

[52] Y. Tamura, H. Adachi, J.-I. Osuga et al., "FEEL-1 and FEEL-2 are endocytic receptors for advanced glycation end products," Journal of Biological Chemistry, vol. 278, no. 15, pp. 12613-12617, 2003.

[53] H. Adachi and M. Tsujimoto, "FEEL-1, a novel scavenger receptor with in vitro bacteria-binding and angiogenesis-modulating activities," Journal of Biological Chemistry, vol. 277, no. 37, pp. 34264-34270, 2002.

[54] S. Kim, S.-Y. Park, S.-Y. Kim et al., "Cross Talk between engulfment receptors stabilin-2 and integrin $\alpha \mathrm{v} \beta 5$ orchestrates engulfment of phosphatidylserine-exposed erythrocytes," Molecular and Cellular Biology, vol. 32, no. 14, pp. 2698-2708, 2012.

[55] S.-Y. Park, M.-Y. Jung, H.-J. Kim et al., "Rapid cell corpse clearance by stabilin-2, a membrane phosphatidylserine receptor," Cell Death and Differentiation, vol. 15, no. 1, pp. 192-201, 2008.

[56] S. V. Kyosseva, E. N. Harris, and P. H. Weigel, "The hyaluronan receptor for endocytosis mediates hyaluronan-dependent signal transduction via extracellular signal-regulated kinases," The Journal of Biological Chemistry, vol. 283, no. 22, pp. 15047-15055, 2008.

[57] M. S. Pandey and P. H. Weigel, "Hyaluronic acid receptor for endocytosis (HARE)-mediated endocytosis of hyaluronan, heparin, dermatan sulfate, and acetylated low density lipoprotein (AcLDL), but not chondroitin sulfate types A, C, D, or $\mathrm{E}$, activates NF- $\kappa \mathrm{B}$-regulated gene expression," The Journal of Biological Chemistry, vol. 289, no. 3, pp. 1756-1767, 2014.

[58] P. H. Weigel, M. S. Pandey, and E. N. Harris, "A HARE/STAB2mediated sensing system to monitor tissue biomatrix homeostasis and stress," in Structure and Function of Biomatrix: Control of Cell Function and Gene Expression, E. A. Balazs, Ed., pp. 293-314, Matrix Biology Institute, Edgewater, NJ, USA, 2012.

[59] S.-Y. Park, S.-Y. Kim, M.-Y. Jung, D.-J. Bae, and I.-S. Kim, "Epidermal growth factor-like domain repeat of stabilin-2 recognizes phosphatidylserine during cell corpse clearance," Molecular and Cellular Biology, vol. 28, no. 17, pp. 5288-5298, 2008.

[60] K. Schledzewski, C. Géraud, B. Arnold et al., "Deficiency of liver sinusoidal scavenger receptors stabilin-1 and -2 in mice causes glomerulofibrotic nephropathy via impaired hepatic clearance of noxious blood factors," Journal of Clinical Investigation, vol. 121, no. 2, pp. 703-714, 2011.

[61] M. A. Simpson, J. A. Weigel, and P. H. Weigel, "Systemic blockade of the hyaluronan receptor for endocytosis prevents lymph node metastasis of prostate cancer," International Journal of Cancer, vol. 131, no. 5, pp. E836-E840, 2012.

[62] J. F. Collawn, M. Stangel, L. A. Kuhn et al., “Transferrin receptor internalization sequence YXRF implicates a tight turn as the structural recognition motif for endocytosis," Cell, vol. 63, no. 5, pp. 1061-1072, 1990.

[63] M. Spiess, "The asialoglycoprotein receptor: a model for endocytic transport receptors," Biochemistry, vol. 29, no. 43, pp. 10009-10018, 1990.

[64] E. J. Filardo, P. C. Brooks, S. L. Deming, C. Damsky, and D. A. Cheresh, "Requirement of the NPXY motif in the integrin beta3 subunit cytoplasmic tail for melanoma cell migration in vitro and in vivo," Journal of Cell Biology, vol. 130, no. 2, pp. 441-450, 1995.

[65] W. J. Chen, J. L. Goldstein, and M. S. Brown, "NPXY, a sequence often found in cytoplasmic tails, is required for coated pit-mediated internalization of the low density lipoprotein receptor," The Journal of Biological Chemistry, vol. 265, no. 6, pp. 3116-3123, 1990. 
[66] Y. Li, M. P. Marzolo, P. Van Kerkhof, G. J. Strous, and G. Bu, "The YXXL motif, but not the two NPXY motifs, serves as the dominant endocytosis signal for low density lipoprotein receptor-related protein," Journal of Biological Chemistry, vol. 275, no. 22, pp. 17187-17194, 2000.

[67] D. J. Mahoney, B. Mulloy, M. J. Forster et al., "Characterization of the interaction between tumor necrosis factor-stimulated gene- 6 and heparin: implications for the inhibition of plasmin in extracellular matrix microenvironments," Journal of Biological Chemistry, vol. 280, no. 29, pp. 27044-27055, 2005. 

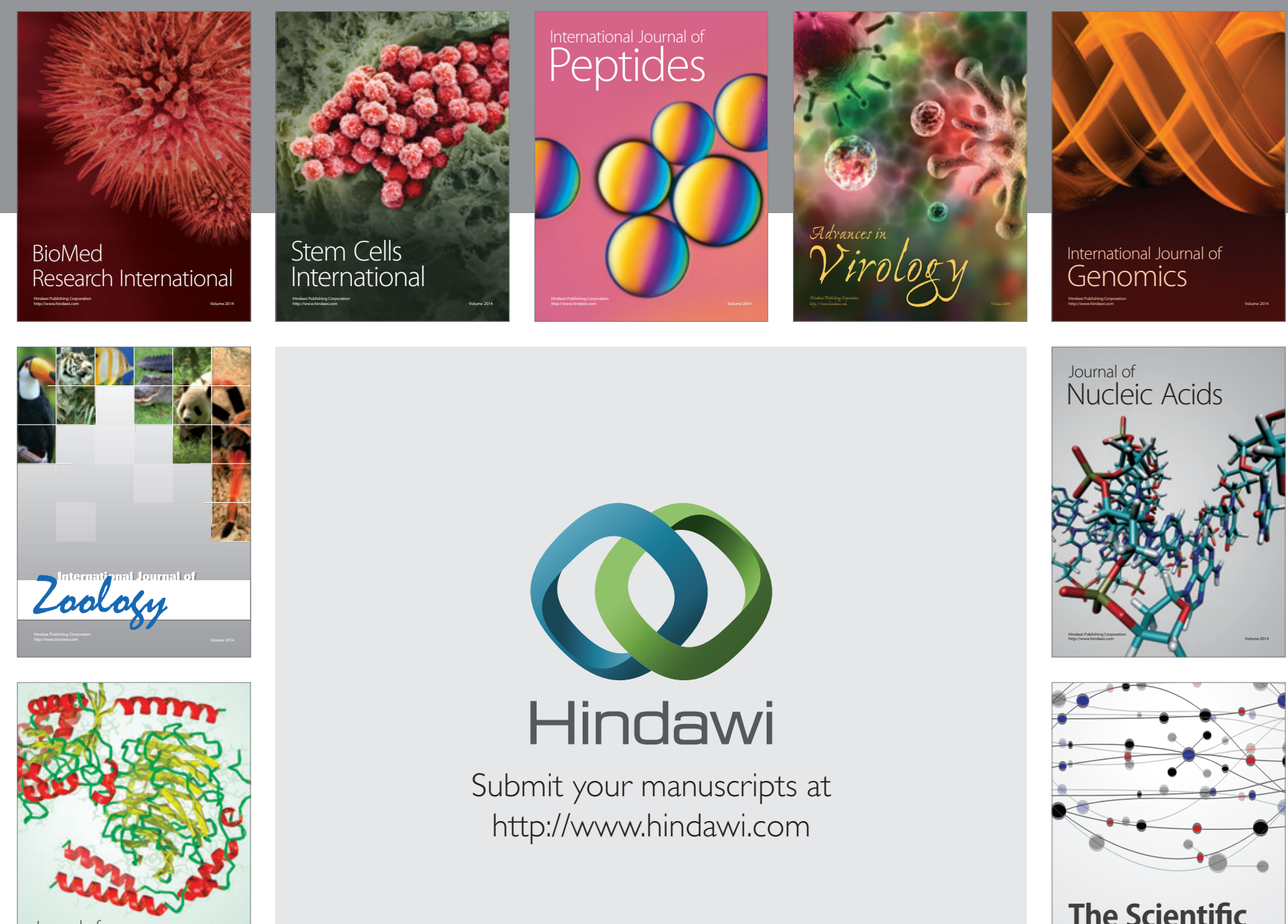

Submit your manuscripts at

http://www.hindawi.com

Journal of
Signal Transduction
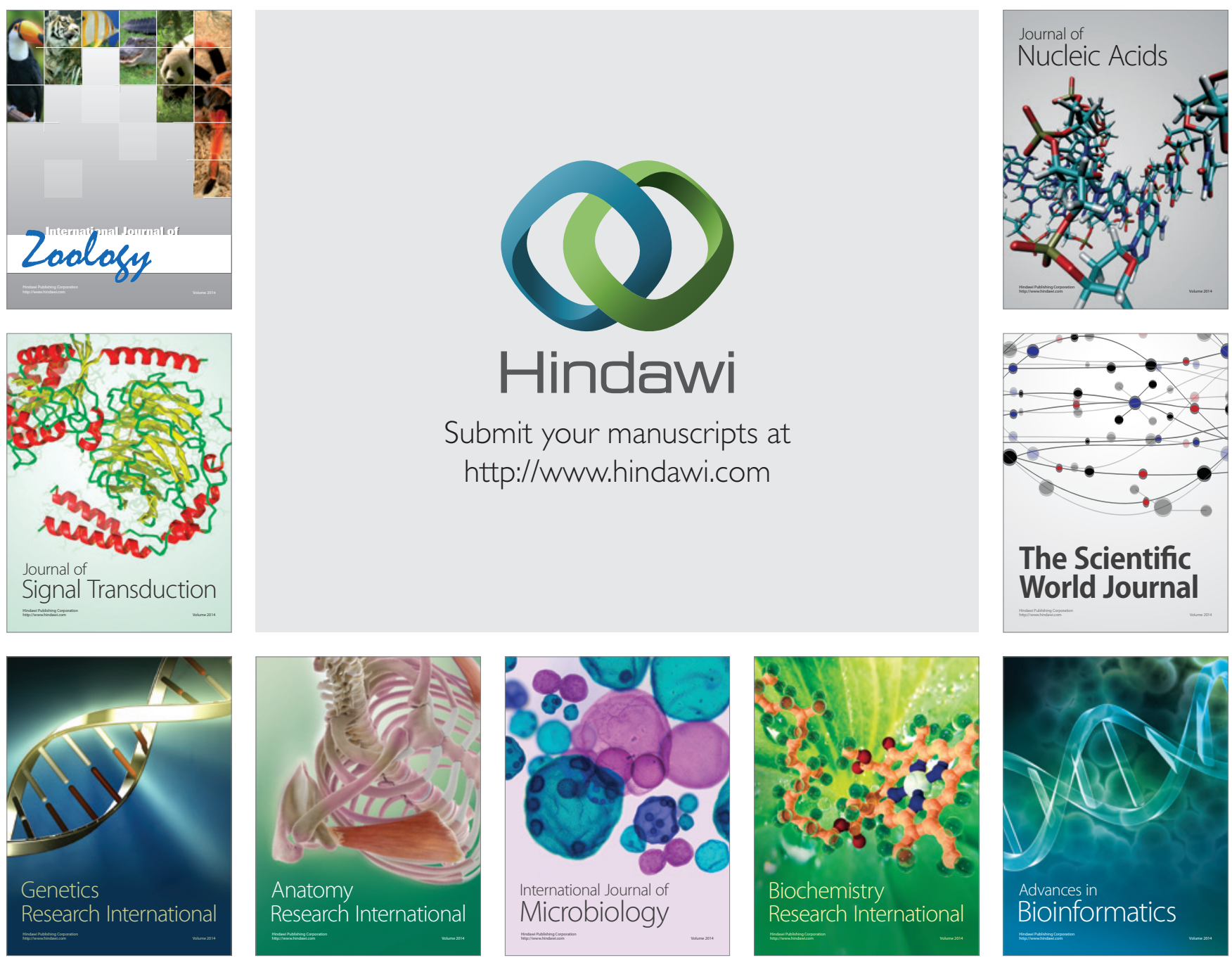

The Scientific World Journal
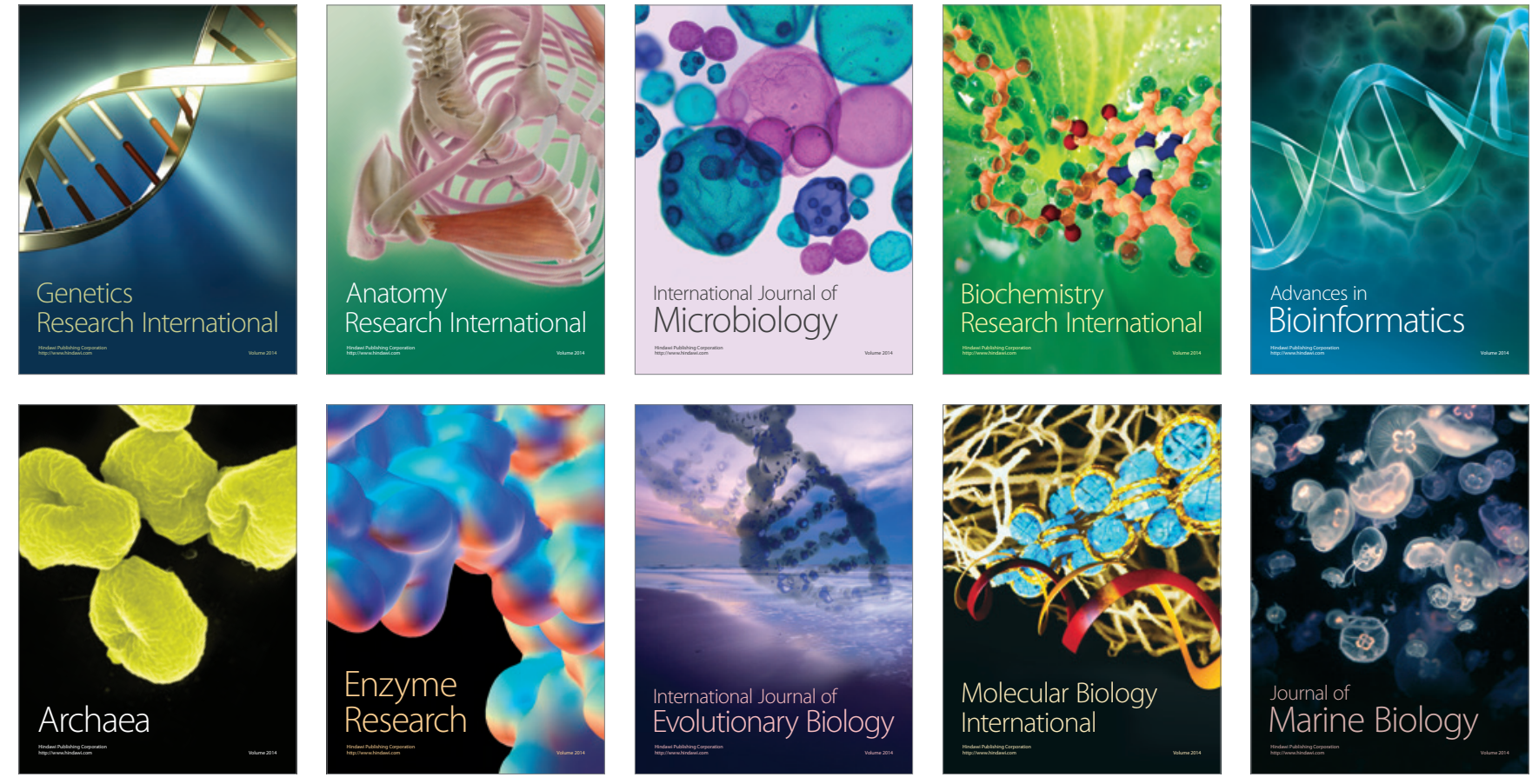